\section{Effects of prey movement and background on predatory behavior of chameleons}

\author{
HENRY R. ASKEW. MARILYN MUSIMECI, LESLEY SLOANE, and LINDA STEPHAN \\ Fordham University, Bronx, N.Y. 10458
}

Four small populations of American chameleons (Anolis carolinensis) were tested to determine the effects on predation of movement of prey and the color of the background on which the prey is presented. Results indicated that movement of the prey was critical to elicit stalking and eating, while background coloration had only a minor influence. An observed interaction of dominance and feeding behavior in the populations was also discussed. killed by keeping them in a freezer for $24 \mathrm{~h}$
An examination of the literature indicates that very little has been done on feeding behavior in reptiles. Hence, in this study the authors have attempted to explore possible factors that may be important in eliciting predatory or feeding behavior in the American chameleon. The existence of a well developed visual system in lizards (Matthews \& Knight, 1963) led to the varying of two visual characteristics of the prey: its movement and the background context on which it is presented.

\section{METHOD}

The Ss were 20 male and 20 female chameleons, Anolis carolinensis. They were maintained in four separate populations each consisting of 5 males and 5 females. The populations were housed in $15 \times 15 \times 15$ in. glass terrariums.

A 2 by 4 repeated measures factorial design was used to test each of the populations with either moving or nonmoving mealworms presented on a background colored with white, black, light brown, or a mixed green. In order to vary prey movement, mealworms were presented either living or dead to the populations. The dead mealworms were and then thawing them $1 \mathrm{~h}$ preceding the test session. Immediately before a session, both live and dead mealworms were dipped in water to attempt to reduce differences in temperature, odor, and visual appearance. This freezing procedure did not appear to the Es to alter the physical appearance of the worms significantly.

The four backgrounds were constructed of $15 \times 15$ in. heavy cardboard, and were placed on the floor of the terrariums 2

days prior to testing. Test sessions began when five mealworms were placed on the background. Presentation was accomplished by placing the mealworms in a small box, inverting the box on the floor of the terrarium, and then removing the box and exposing the mealworms. Test sessions lasted a maximum of $30 \mathrm{~min}$. During this time the E simply observed the population and recorded when each of the five mealworms was eaten (normally a single chameleon did not eat more than two mealworms). The session was terminated before the $30 \mathrm{~min}$ if all of the mealworms were eaten.

The eight test sessions ( 2 movement conditions by 4 backgrounds) were given $48 \mathrm{~h}$ apart, and in a randomly determined order for each of the populations. After each test session, the background was removed and the animals were given an unlimited supply of live mealworms for $1 \mathrm{~h}$. After this free-feeding period, remaining mealworms were removed and the background appropriate for the next test session was put in place. As a result, the animals had always been deprived of food for at least $47 \mathrm{~h}$ prior to each session.

\section{RESULTS AND DISCUSSION}

The number of mealworms eaten during the 30-min test session as a function of movement and background is given in Table 1. A three-way single observation per cell analysis of variance (Winer, 1962, p. 290) showed significant effect due to both movement $(\mathrm{F}=79.1, \mathrm{df}=1 / 3$, $\mathrm{p}<.01)$ and background $(\mathrm{F}=5.27$, $\mathrm{df}=3 / 9, \mathrm{p}<.05)$. First, as can be seen from the table, almost all of the mealworms that were eaten were alive. That this difference was due primarily to

Table 1

Number of Live and Dead Mealworms Eaten by Four Populations of Chameleons on Four Colored Backgrounds

\begin{tabular}{ccccccccc}
\hline & \multicolumn{4}{c}{ Live } & & \multicolumn{2}{c}{ Dead } \\
Populations & Green & Brown & Black & White & Green & Brown & Black & White \\
\hline I & 5 & 5 & 0 & 4 & 0 & 0 & 0 & 2 \\
II & 5 & 5 & 5 & 5 & 0 & 0 & 0 & 0 \\
III & 4 & 4 & 3 & 5 & 1 & 0 & 0 & 0 \\
IV & 5 & 4 & 0 & 5 & 0 & 0 & 0 & 0 \\
\hline
\end{tabular}

movement was apparent to the Es. When dead mealworms or immobile live mealworms were placed in the terrarium they were almost always completely ignored. On the other hand, moving mealworms readily attracted what can only be described as intense visual tracking by virtually all animals in the population and stalking by some of the animals. Further, this orientation and approach toward the prey seemed to cease if the prey animal stopped moving.

With respect to background, it appeared from the table that the black background was somewhat less effective than the others in eliciting predation. However, this result should only be taken as suggestive given the relatively small $F$ value coupled with questionable satisfaction of the assumptions underlying the statistical analysis.

An interesting incidental finding in the present study was that dominance in the population appeared to interact with feeding behavior. Specifically, it was observed that in all four populations a single male became dominant and would frequently initiate aggressive displays and attacks and would readily physically displace any of the others in the population. Further, the dominant animal in each population appeared to exert a strong influence on the feeding behavior of the other animals in the population in that the others would delay feeding for a considerable period of time unless the dominant animal ate, at which time they would much more readily engage in stalking and eating. As a result of this apparent interaction, although at least 3 of the 10 animals in each population were typically involved in eating the live mealworms, it could be argued that the differences between the different movement and background conditions in the number of mealworms eaten may be largely due to the thresholds of the single dominant animals rather than the population as a whole. Unfortunately, the extent to which the results are due to the dominant males alone or to some sort of general response of a significant portion of the entire population could not really be assessed utilizing the present design. In any case, this observed interaction of feeding behavior and dominance, coupled with the questions that follow concerning the dynamics of this interaction, would seem to be highly interesting and well worth further analytic study in chameleons.

\section{REFERENCES}

MATTHEWS, L., \& KNIGHT, M. The senses of animals. New York: Philosophical Library. 1963.

WINER, B. J. Stotistical principles in experimental design. New York: McGraw-Hill, 1962. 